Artigos

\title{
ABORDAGENS SOCIOLÓGICAS DA QUESTÃO AMBIENTAL: CONTRIBUIÇÕES E LIMITES CONCEITUAIS
}

\section{SOCIOLÓGICAL APROACHES OF ENVIRONMENTAL ISSUES: CONTRIBUTIONS AND CONCEPTUAL LIMITS}

\author{
Pedro Robertt \\ Prof $^{\circ} \operatorname{Dr}^{\circ}$ Adjunto do Instituto de Sociologia e Política \\ da Universidade Federal de Pelotas, UFPel
}

\begin{abstract}
RESUMO
$\mathrm{O}$ artigo traça um panorama geral de algumas das principais abordagens, na área da sociologia, sobre a questão ambiental. Seu objetivo é mostrar que não existe uma perspectiva sociológica única sobre essa questão. Examinam-se cinco abordagens analíticas: a sistêmica, a valorativacomunicativa, a das contradições do capitalismo, a do risco e a pós-moderna. $\mathrm{Na}$ exposição são apresentadas as diversas abordagens assinalando suas principais características; deixando para a parte de considerações finais, as contribuições e limites conceituais de cada uma delas. $\mathrm{O}$ estudo mostra que existem diálogos e entrecruzamentos entre as diversas leituras da questão ambiental, concluindo-se que a análise pós-moderna é aquela que consegue incorporar desde uma visão peculiar e critica as outras perspectivas.
\end{abstract}

Palavras-chave: questão ambiental, abordagens sociológicas, teoria.

\begin{abstract}
The central purpose of this article is to provide an overview of some environmental top approaches in the field of sociology. The main point illustrates that there is not just one prospect on this issue. It examines five analytical approaches, such as: systemic, evaluative-communicative, contradictions of capitalism, riskand and postmodern. Therefore, it shows the different approaches highlightingits key features and it also presents the conceptual contributions and limitations of each one in the final consideration. As a result, this study reveals that is possible to observe dialogues and crossovers between different readings of environmental issues, concluding that the postmodern analysis is the one that succeed to incorporate from a singular vision to other critical perspectives.
\end{abstract}

Key words: environmental issues, sociological approaches, theory 


\section{INTRODUÇÃO}

$\mathrm{O}$ artigo, aqui apresentado, traça um panorama geral de algumas das principais perspectivas analíticas, na área da sociologia, sobre a questão ambiental ${ }^{1}$. Esta se constitui em um tema de debate desde finais dos anos sessenta e inícios dos anos setenta, o que é amplamente documentado pela bibliografia da área. A partir dessa constatação, o argumento que se pretende desenvolver é de que existem, hoje, diversas abordagens que interpretam de modo diferente a denominada questão ambiental e apresentar-se-á, em linhas gerais, de cada uma delas suas principais características, contribuições e limites.

Nesta exposição examinam-se cinco perspectivas sobre a questão ambiental: a sistêmica, a valorativa-comunicativa, a das contradições do capitalismo, a do risco e a pós-moderna. A seguir são apresentadas, a partir de alguns representantes dessas concepções as principais características de cada uma delas. Posteriormente, nas considerações finais, analisam-se tais perspectivas em conjunto, explicitando contribuições analíticas e limites conceituais de cada uma delas.

\section{A PERSPECTIVA SISTÊMICA ${ }^{2}$}

A abordagem sistêmica toma como ponto de partida a degradação das bases biofísicas que permitem a sobrevivência da espécie humana. O reconhecimento e a resolução da problemática ambiental envolvem a determinação de alguns subsistemas que precisam sofrer alterações. Assim são observados, para o tratamento dessa questão, aspectos de "mentalidades, valores e atitudes", do conhecimento intradisciplinar no interior da ciência, da coordenação entre sistemas científicos e políticos e de diversos elementos institucionais.

No que diz respeito à produção de conhecimento científico tende-se a acentuar a necessidade de pesquisas que levem em conta aspectos sociais, econômicos, culturais e político-institucionais. Isso denota que, para essa postura teórica, o meio ambiente é o resultado da integração entre diversos subsistemas. Isso implica, também, que os desequilíbrios produzidos em cada um dos subsistemas refletem sobre os outros e sobre o conjunto. O meio ambiente não representa então um

\footnotetext{
${ }^{1}$ Este texto é resultado de uma reflexão do autor a partir da disciplina "Ecologia Política", ministrada no segundo semestre de 2010, no Curso de Especialização da Faculdade de Direito da Universidade Federal de Pelotas. Não se pretende esgotar as perspectivas sociológicas da questão ambiental, mas, sim apresentar aquelas que participam com maior ênfase do debate.

${ }^{2}$ A exposição da perspectiva sistêmica é feita de acordo com Paulo Freire Vieira (1998).
} 
objeto estático ou isolado que possa ser reduzido, por exemplo, às noções de natureza e/ou paisagem, ele apresentaria sim "uma relação de interdependência".

De acordo com Paulo Freire Vieira (1998, p. 49), autor representativo dessa abordagem, o meio ambiente seria um "conjunto de componentes físico-químicos e biológicos, associado a fatores socioculturais suscetíveis de afetar, direta ou indiretamente, a curto ou longo prazos, os seres vivos e as atividades humanas no âmbito globalizante da ecosfera".

A noção de desequilíbrio é central nessa concepção. A questão ambiental é pensada em termos de não equilíbrio de alguns subsistemas. De um lado, têm-se desequilíbrios originados pela ausência de regulação do subsistema econômico e, de outro, um crescimento exponencial do componente demográfico. O crescimento da população, no nível planetário, é um elemento fundamental haja vista que aumentaria os impactos das ações de destruição sobre o planeta.

Uma das teses principais apontadas é a de que um sistema sociocultural atua de forma negativa sobre um sistema socioambiental. Por sua vez, aquele estaria formado por quatro subsistemas relacionados entre si: o biológico, o econômico, o político e o cultural.

Em termos metodológicos, para a concepção sistêmica, a problemática ambiental pode ser abordada satisfatoriamente a partir de ações de planejamento. Desse modo, o reconhecimento do comportamento de algumas variáveis de tipo social, político e cultural possibilitará a criação de metodologias de planejamento. Nesse sentido, de um lado, a construção de modelos e as análises prospectivas são centrais no que diz respeito a ações corretivas ou transformadoras e, de outro, existe um forte questionamento à inexistência de indicadores válidos da questão ambiental.

Às ideias de planejamento e de desenvolvimento de metodologias associa-se a de existência de custos socioambientais, os quais seriam resultado dos processos de modernização da área econômica. O planejamento e a criação de novas metodologias permitiriam antecipar a emergência de impactos destrutivos bem como determinar cursos prováveis de ação com efeitos positivos sobre o meio ambiente e a qualidade de vida. A ação de planejamento supõe, aliás, contar com métodos de abordagem da realidade ambiental orientados à captação de informação, tendo por objetivo a racionalização dos processos de tomada de decisão relativos aos denominados sistemas ecossociais.

Uma proposta de desenvolvimento ecológico implica, nessa linha de análise, valorizar a potencialidade dos chamados "recursos naturais e humanos". Para tanto, tratar-se-ia de minimizar os custos sociais e ecológicos. Na visão de Freire Vieira (1998), uma nova "concepção estratégica" precisaria ser elaborada, fundamentada em quatro componentes: no crescimento econômico vinculado a metas sociais de caráter prioritário, na prudência ou sustentabilidade ecológica (isto é, 


\section{Abordagens sociológicas da questão ambiental: contribuições e limites conceituais}

no abandono de uma relação arrogante com a natureza), na valorização de participação da sociedade civil e na viabilidade econômica.

A perspectiva sistêmica mostra que a questão ambiental constitui um todo integrado. Alterações em algumas partes do sistema social teriam efeitos sobre outras partes. Essa é uma contribuição inestimável dessa concepção para o estudo da problemática ambiental. Outra contribuição consistiria no estabelecimento da necessidade de ações de planejamento diante dessa questão. Em termos práticos, busca-se elaborar medições que permitam uma melhor compreensão para uma melhor intervenção. Porém, persistem nela vários elementos passíveis de crítica, tais como: a avaliação da questão ambiental em termos de custos e recursos, reduzindo-a a uma concepção economicista; a ausência de uma análise que avalie agentes sociais que atuam em sentidos diversos em relação ao meio ambiente, por mais que possa se valorizar a participação popular (esta entra mais como uma variável interveniente diante de fatos já consumados); o predomínio de uma visão que enfatiza relações de interdependência entre subsistemas em detrimento de outra que leve em conta atores ou agentes; a responsabilização do crescimento demográfico como uma variável de forte peso explicativo, como se a depredação da natureza se resumisse ao aumento do número de pessoas que habitam o planeta ${ }^{3}$.

\section{PERSPECTIVA VALORATIVA-COMUNICATIVA ${ }^{4}$}

Na concepção valorativa-comunicativa a crise ecológica global é percebida como resultado da dualidade radical terra-mundo. O mundo é avaliado como sendo uma segunda realidade, isto é, implica a ocupação humana da Terra. Os problemas ambientais abrangem os efeitos não esperados do modelo capitalista industrialista, que é, aliás, o modelo dominante de desenvolvimento econômico, tendo no consumo o elemento legítimo de sustentabilidade limitada do planeta.

Uma abordagem realista, nessa linha de análise, supõe a tomada de decisões em um cenário complexo, envolvendo produção, consumo, crescimento demográfico e qualidade ambiental. Junto com isso, um elemento central é configurado pelo debate em torno aos valores que regem a sociedade humana como um todo.

Reconhece-se o mundo moderno como sendo cada vez mais global e internacional e, concomitantemente, o ambientalismo como um movimento histórico e global. Esse último estaria

\footnotetext{
${ }^{3}$ Se fosse assim deveria de ser provado que países mais populosos afetam de maneira mais negativa o meio ambiente. ${ }^{4}$ Esta perspectiva é construída a partir de Héctor Ricardo Leis (1998).
} 
baseado em um conjunto de valores e ideias e constituiria em si mesmo uma ideologia, no sentido mais usual da palavra, como a ela se referem o liberalismo, o conservadorismo ou o socialismo.

Há na perspectiva valorativa-comunicativa uma busca de aproximação e convergência entre aspectos ecológicos e processos econômicos. O seu diagnóstico indica que a razão instrumental é insuficiente para atender a problemática ambiental, ainda mais quando essa é reduzida à ação do mercado. Em consequência deveria haver uma profunda mudança nos atores, tanto de comportamento quanto de mentalidade.

A relação ecologia/valores é colocada em termos de exigências da Terra de ser considerada como um bem comum. Assim como a Terra (com "T" maiúscula) adquire a condição de Sujeito, a humanidade também obteria essa condição atribuindo-se a ela a busca de valores globais. Para tanto, argumenta-se que seria necessário, um fenômeno de persuasão sobre os interesses particulares, a emergência de regras e instituições aceitas por diversos atores e, além disso, o imperativo categórico da necessidade de mudanças.

O diagnóstico sobre a realidade ambiental contemporânea afirma, também, a falta de compreensão e de vontade política, caracterizadas pelo dilema de quem agiria primeiro a favor do meio ambiente (se os atores observariam sempre a ação dos outros atores para se decidir a agir, isto levaria a um impasse) e pela primazia de postulados neoliberais e do mercado mundial.

As causas da crise ecológica global seriam a exploração e a gestão dos bens comuns efetuadas por atores políticos e econômicos, assim como, a orientação dominante da ação racional, individualista e instrumental. O mercado nessa linha de análise não apenas não atenderia a valores universais como também acabaria premiando os atores econômicos mais poluidores ${ }^{5}$. A relação entre o mercado e a ecologia, também, coloca a questão de como fazer para que o primeiro atenda as exigências da segunda. Destaca-se que no mercado predominam valores materiais característicos da razão instrumental. Tratar-se-ia de descolonizar os comportamentos individualistas presentes na sociedade. Isso implicaria a regulação do mercado, isto é, controlar seus efeitos, mas, sem pretensões de eliminá-lo.

Em grande parte das Ciências Sociais teria predominado uma concepção utilitarista apriorística da cultura contemporânea. Em contraste, retirar frase (começar daqui) o ambientalismo é para Leis (1998), uma condição ético-comunicativa, o que constituiria, aliás, o seu elemento mais poderoso. $\mathrm{Na}$ avaliação que se fez da Conferência sobre meio ambiente realizada no Rio de Janeiro, em 1992, o mais relevante não seriam os acordos ou debates entre representantes dos governos, pelo 


\section{Abordagens sociológicas da questão ambiental: contribuições e limites conceituais}

contrário, o mais importante seria, conforme Leis (1998), a emergência de uma "sociedade civil planetária".

$\mathrm{Na}$ incorporação do paradigma habermasiano da comunicação, trata-se de observar a constituição de um espaço público comunicativo. Elementos centrais nesse processo seriam: os consensos transnacionais legítimos, a governança global e a comunicação de argumentos éticos e racionais. $\mathrm{O}$ ambientalismo, na postura valorativa-comunicativa apontaria para outra dimensão da análise habermasiana que seria o mundo da vida (lebenswelt). Em suma, ele poderia ser definido como uma "condição ético-comunicativa, capaz de orientar ações de forma convergente em contextos diversos e com atores de interesses divergentes” (LEIS, 1998, p. 32).

Os componentes valorativos e comunicacionais situariam essa linha de pensamento dentro do enfoque teórico da ação comunicativa. A perspectiva valorativa-comunicativa teria a virtude de apontar para aspectos ausentes em outras leituras, como o da ética ambiental. Sem dúvidas, sem consciência ambiental não há possibilidade de enfrentar essa problemática. Contudo, a referência difusa de atores políticos e econômicos e a responsabilização da sociedade, como entidade geral (até metafísica), indicam que faltam a essa perspectiva elementos materiais e agonísticos presentes na problemática ambiental.

\section{A PERSPECTIVA DAS CONTRADIÇÕES CAPITALISTAS}

A perspectiva analítica das contradições capitalistas responde a uma interpretação baseada no pensamento de Marx. Esta seção apresenta como referência um artigo de James O'Connor $(2002)^{6}$, no qual o autor, inicia seu argumento enfatizando a ambiguidade de expressões como as de capitalismo sustentável, de agricultura sustentável ou de uso sustentável da energia e dos recursos. A mesma expressão desenvolvimento sustentável, que tem atingido uma forte legitimidade na linguagem acadêmica e extra-acadêmica, é também avaliada como ambígua, o próprio O’Connor demonstra a força simbólica que tem adquirido o termo sustentabilidade, ao se perguntar por exemplo, afinal, quem se oporia a ela?

A ambiguidade das expressões associadas à noção de sustentabilidade, argumenta o referido autor, está na polissemia desse último termo. Sustentabilidade pode significar "preservar" um estado de coisas, "fornecer" meios de vida ou “não ceder". Esses três significados podem, aliás, ser vinculados, respectivamente, a três processos: à acumulação capitalista, aos meios de vida dos

${ }^{6} \mathrm{~A}$ lista de autores que trabalham sob esta perspectiva é ampla. Entre outros pode se consultar Altvater (1995, 2007) e Foladori (2001). 
povos e à persistência em manter um modo de vida. Essa diversidade de sentidos aponta para o fato, nessa linha de análise, de ser a sustentabilidade, então, uma questão ideológica e política antes que ecológica e econômica. Existe para O’Connor um outro sentido em relação ao conceito de sustentabilidade, àquele de "sustentabilidade ecológica". Porém, de um lado, não há acordo sobre o significado exato dessa expressão e, de outro, elementos como a biodiversidade ou a saúde do planeta poucas vezes, diz o autor, são problematizados em termos da ciência ecológica e menos ainda, poder-se-ia dizer: na ciência econômica. Tal análise leva a O'Connor a afirmar que um capitalismo sustentável é improvável a curto prazo e pouco provável a longo prazo.

Duas grandes contradições colocam em relação o capitalismo com o meio ambiente. A primeira é a contradição do capitalismo e a natureza da acumulação capitalista. Trata-se da contradição entre apropriação privada e produção social. De um lado, quanto maior a exploração da força de trabalho maior o lucro produzido. De outro, isso tem como consequência maiores dificuldades para realizar o lucro no mercado já que a redução de custos tem como consequência uma força de trabalho com menor poder aquisitivo. A regulação dessa primeira contradição é feita por meio do estabelecimento de regras macroeconômicas, para as quais é central o papel do Estado. Contudo, existem hoje dificuldades de regulação global, basicamente devido ao enfraquecimento dos sistemas estatais.

A segunda contradição refere-se a um problema aparentemente insolúvel do capitalismo. Trata-se da redução dos "lucros marginais", como resultado da contradição entre o capital e a natureza. Aponta-se aqui para uma crise econômica do lado dos custos. Esta é determinada pelo incremento dos custos do trabalho, dos recursos naturais, da infraestrutura e do espaço.

Uma primeira maneira de se desenvolver essa contradição ocorre quando capitais individuais obtêm lucros degradando as condições materiais e sociais de sua produção. A deterioração das condições de trabalho, a degradação dos solos e das infraestruturas urbanas, tudo isso são custos que crescem com o próprio dinamismo do capitalismo. Esses trazem, também, custos sanitários, queda na produtividade da terra e custos de congestão e vigilância urbana.

Uma segunda maneira de desenvolvimento dessa contradição é resultado da ação dos movimentos sociais e do ambientalismo, na medida em que exigem a contribuição do capital para a preservação e restauração das condições de vida, ou seja, uma melhor atenção da saúde, a recuperação do solo e a qualidade de vida dos bairros urbanos entre outras questões.

Os limites do crescimento não são resultado da escassez, mas sim, do alto custo que passam a ter as denominadas condições de produção. $\mathrm{O}$ aumento dos custos gera uma ameaça à 


\section{Abordagens sociológicas da questão ambiental: contribuições e limites conceituais}

rentabilidade do capital, levando ao Estado e às empresas a racionalizar os diversos tipos de mercado - como o de trabalho, o de insumos e o de matérias primas, por exemplo - bem como as normas de uso da terra.

A queda da rentabilidade pressiona os capitais individuais no sentido de redução do tempo de produção da mercadoria. Além disso, o capital procura movimentar-se mais rapidamente, mesmo na direção de outras formas econômico-sociais mais antigas. Nesse sentido, para o capital, a ação dos movimentos de trabalhadores e de outros movimentos sociais torna-se obstáculos que precisam ser superados.

Em suma, os custos do capital elevam-se por dois motivos: de um lado, capitais individuais têm poucos ou nenhum incentivo para utilizar as condições de produção de modo sustentável, sobretudo, em momentos econômicos ruins; e de outro, os custos elevam-se pela própria ação dos movimentos sociais e do ambientalismo.

A dinâmica capitalista acaba, portanto, tendo como resultado uma crise de custos. A pergunta que surge, então, é: como se administra uma crise de custos? Segundo O’ Connor a pior solução ocorre quando capitalistas individuais enfrentam de um lado custos crescentes e, de outro, demandas decrescentes. Nesse caso, optam por fazer um corte maior de custos, tendo como resultado a intensificação das duas tendências citadas acima. Outra solução individual seria dada por medidas ambientais tais como a reciclagem, a redução de elementos contaminantes e a limpeza do meio ambiente.

Em conjunto a melhor solução para o capital - independentemente da sociedade e da natureza - é reestruturar as condições de produção e fazer importantes investimentos. No entanto, isso depende fundamentalmente do agir do Estado. Uma solução mais consistente passaria por fortes investimentos na reestruturação da produção, aumentando, portanto, a produtividade e diminuindo os custos. Nessa alternativa, seria estimulada a produtividade de longo prazo, mas, em contrapartida, seriam prejudicados os custos de curto prazo.

$\mathrm{O}$ argumento desenvolvido, afirma o supracitado autor, é no sentido de pensar teoricamente a sustentabilidade do capitalismo. Mas na prática o que vem ocorrendo? A resposta é de que apenas nos estados liberais democráticos há previsão de um planejamento integrando os elementos ambiental, urbano e social. Contudo, apesar desse avanço, choca-se com uma administração antidemocrática e insensível aos problemas ambientais. A lógica e dinâmica do capital, como pôde ser observado ao longo desta seção, não vai no mesmo sentido de uma qualidade ecológica, urbana e social. Isso resulta numa contradição com a geração de soluções políticas para a crise das 
condições de produção. Apesar das prevenções não existe em nenhum país capitalista central um planejamento integrado. Uma solução capitalista para a segunda contradição, a que refere à perda de lucros marginais do capital, é então remota, para O’ Connor. O autor conclui que a ideia de um “capitalismo ecológico ou sustentável” carece de coerência teórica e não vem sendo concretizada institucionalmente.

\section{TEORIA DO RISCO E AMBIENTE}

A teoria da sociedade do risco é uma das construções conceituas mais inovadoras das ciências sociais contemporâneas e um de seus principais representantes é o sociólogo alemão Ulrich Beck. E são, principalmente, sobre as ideias deste autor que está fundamentada esta seção ${ }^{7}$.

Nessa perspectiva, a modernização envelheceria e mostraria - para além de que alguns a concebam como um processo independente - uma outra faceta: a de nos levar para uma sociedade do risco. Essa é definida como uma: "fase de desenvolvimento da sociedade moderna em que os riscos sociais, políticos, ecológicos e individuais, por ela gerados, fogem de forma crescente das instituições de controle e segurança da sociedade industrial” (BECK, 1999, p. 32, tradução do autor).

A sociedade do risco teria, então, duas fases: uma primeira, residual, em que os perigos são gerados sistematicamente, mas não são tematizados no espaço público e por esse motivo, os perigos gerados não são ainda o centro dos conflitos sociais, devido ao pressuposto do controle completo. A segunda fase caracterizar-se-ia pelo debate em torno de conflitos, estes que são resultado dos perigos advindos da sociedade industrial. Nessa fase ulterior, a sociedade industrial passa-se a auto observar e criticar como uma sociedade de risco.

A Sociedade do risco, numa época de modernidade reflexiva ${ }^{8}$, não é uma opção, afirma Beck, ela seria resultado de uma modernização independente e cega. A questão do risco passa a ser uma questão tematizada, mas, que não pode ser resolvida. Os tipos de conflito sofrem importantes mudanças, enquanto na sociedade industrial eles eram distributivos, estando portanto relacionados a goods sociais e envolvendo classes sociais, na sociedade do risco trata-se da distribuição de bads

\footnotetext{
${ }^{7}$ Outros autores como Anthony Giddens e Cristopher Lash vêm trabalhando a noção de risco como categoria de análise que permite compreender melhor o estágio atual da modernidade. A esse respeito, pode ser consultada a obra conjunta de Giddens, Lash e Beck (1997). Esta seção é fundamentada, basicamente, em Beck (1999).

${ }^{8}$ Embora se desenvolva este conceito, algumas linhas adiante, a obra, já mencionada, de Giddens, Beck e Lash (1997) pode ser consultada para aprofundamento. .
} 


\section{Abordagens sociológicas da questão ambiental: contribuições e limites conceituais}

sociais, isto é, riscos associados à tecnologia atômica e química, à pesquisa genética, à problemática ambiental, ao armamentismo e ao processo de pauperização da humanidade.

$\mathrm{Na}$ sociedade do risco, o que está em jogo é um desenvolvimento da modernidade em que prevalecem ameaças que são resultado do caminho adotado pela sociedade industrial. Isso interpela as sociedades em termos da necessidade de sua auto limitação. Para Beck, coloca-se em discussão o sistema industrial e a mudança de época em três esferas distintas: em primeiro lugar, na relação da moderna sociedade industrial com os recursos da natureza e da cultura, na qual surge como prioridade a questão do consumo de reservas; em segundo lugar, na relação da sociedade com os perigos por ela gerados, os quais, aliás, superam o nível das representações; e em terceiro lugar, no processo de individualização que está associado à dissolução, destruição e desencantamento do pensamento moderno no que se refere à criação de ideias coletivas.

A sociedade do risco, para Beck (1998, p. 36, tradução livre do autor): “inicia ali onde falha a segurança prometida nos sistemas de normas sociais em relação aos perigos desencadeados pelas decisões". A Insegurança seria traduzida em riscos sociais, políticos, ecológicos e individuais.

Ameaças e perigos, afirma o autor citado, existiram em todas as épocas. Ser moderno, na realidade, quer dizer que perigos, ecológicos e outros, podem ser resolvidos por meio de decisões humanas e, portanto, não podem ser adjudicados a deuses ou a outras forças sobre-humanas. Isso coloca, hoje, um sério problema de legitimidade, visto que perigos e catástrofes não seriam necessariamente produto de guerras e de ações militares, poderiam sê-lo, também, de decisões humanas que visam a melhoria técnica e econômica. É por isso, argumenta Beck, que os que tomam decisões podem ir para o banco dos réus. Além disso, outros aspectos precisam ser levados em conta para compreender a falha de segurança, tais como: a resposta à pergunta sobre o comportamento dos perigos gerados por decisões, amiúde sob o manto da noção de utilidade, diante das normas que garantiriam seu controle; a própria exigência de controle que aparece questionada, pois, o sistema de normas e as promessas não conseguem dar conta dos perigos gerados; as diferenças culturais na percepção tanto das consequências quanto dos perigos da sociedade industrial; e a entrada na sociedade de risco em um momento em que os perigos ultrapassam os limites da segurança.

A incerteza contemporânea é dada pelo fato de que a sociedade do risco tropeça com o limite do crescimento linear. A modernidade industrial tem resolvido os problemas, por ela mesma gerados, através de incrementos da racionalidade. Como consequência disso, não existiria desde a perspectiva em análise o "problema do meio ambiente", mas sim uma crise profunda da sociedade 
industrial. A questão ambiental seria colocada como resultado do desenvolvimento dessa modernidade linear que tem como pressuposto a possibilidade de controle total, o que justamente não se verificaria em uma época de risco.

O contexto atual da modernidade é dado pelo aumento da desordem e da impossibilidade de cálculo, isto é, da imprevisibilidade das consequências. A modernidade linear tem respondido aos problemas gerados por meio de medidas instrumentais, quer dizer, naquelas baseadas em ações racionais com relação a fins. Em outras palavras, ela responderia com mais técnica, com mais mercado e, ainda, com mais Estado.

A modernidade reflexiva surge como uma resposta à sociedade do risco, mediante um repensar e um reagir. Trata-se, para Beck (1999), de aceitar a ambivalência em todas as esferas e sair da racionalização dominante do Ocidente, fazendo um deslocamento para o contingente e o incerto. A questão do risco em uma sociedade de modernidade reflexiva leva o autor a refletir sobre as questões da democracia e do ambientalismo. A crítica nessa sociedade é democratizada e o ambientalismo constitui-se em termos de um novo projeto realista-utópico mundial. Em tal contexto, trata-se da gestão de conflitos sociais que não são apenas técnicos, em que não estão em jogo apenas verdades científicas, mas sim, formas de apreciar e enfrentar reflexivamente as ameaças.

A democracia na sociedade do risco implica a estruturação política da sociedade por meio de temas como o ambiente, passando a natureza a adquirir, então, o caráter público. Trata-se, em outras palavras, de "natureza pública", em que os conflitos não podem ser tratados como problemas de ordem, mas sim como problemas de risco Contudo, o projeto de construção política precisaria adaptar-se às novas condições, visando uma democracia sem exclusões.

A modernização reflexiva traz consigo o componente crítico da sociedade de risco, argumentando que aquilo considerado funcional e racional converteu-se em ameaça vital, isto é, em disfuncionalidade e irracionalidade. A irrupção, então, de alternativas de autocontrole e de autolimitação abrem as portas para a emergência do fazer político. Modernização reflexiva seria auto ameaça das bases da sociedade industrial e, ao mesmo tempo, conscientização.

\section{A PERSPECTIVA DA CRÍTICA PÓS-MODERNA}

Esta linha de pensamento sobre a perspectiva da crítica pós-moderna tem como um de seus principais expositores o autor mexicano Enrique Leff ${ }^{9}$. A degradação ambiental e o risco de

\footnotetext{
${ }^{9}$ Esta seção está baseada em Leff (2007).
} 


\section{Abordagens sociológicas da questão ambiental: contribuições e limites conceituais}

colapso ecológico planetário bem como o avanço da pobreza e da desigualdade social seriam, nessa concepção, sinais convincentes da crise do mundo globalizado. A sustentabilidade, tema central de final do século XX e início do Século XXI seria, para Leff, considerada como uma falha fundamental na história da humanidade.

Estamos diante, para o referido autor, de uma crise civilizatória. Essa alcança seu momento culminante na modernidade, mas, suas origens devem ser buscadas na concepção do mundo que estabeleceu as bases da civilização ocidental. Nesse sentido, o tempo presente é também um momento de transição de uma modernidade truncada e inacabada para uma pós-modernidade incerta. Esta última, por sua vez, está marcada por um conjunto de valores: diferença, diversidade, democracia e autonomia. Em outras palavras, segundo Leff (ano), estar-se-ia em um processo de transição entre uma modernidade saturada e uma pós-modernidade que está buscando seu caminho.

Esta concepção apresenta uma forte crítica à noção de desenvolvimento sustentável. O raciocínio de Leff, semelhante, também, ao de O’Connor neste aspecto, indica que a ambivalência do discurso da sustentabilidade tem origem na polissemia do termo sustentabilidade: tanto como internalização das bases ecológicas da economia quanto em termos de durabilidade da dinâmica econômica. No caso extremo, a sustentabilidade foi associada, diz o autor, à noção de crescimento econômico sustentado, revelando-se como uma concepção neoliberal do ambiente. Em outras palavras, o ambiente é traduzido em termos de medição no mercado. O sentido crítico do conceito de ambiente, afirma este autor, acabou se perdendo, em uma retórica neoliberal em que o mercado daria o justo valor à natureza. Nessa concepção, amplamente difundida, trata-se então da sustentabilidade da economia antes que a da natureza. A sustentabilidade acabaria sendo, então, um mecanismo extraeconômico de racionalidade capitalista.

O momento presente coloca frente a frente duas racionalidades: uma capitalista e outra ecológica ou ambiental. O confronto é dado entre diversos valores e potenciais, que estão inseridos em diferentes esferas institucionais, com base em paradigmas de conhecimento e com uma legitimidade que está incorporada em classes, grupos e atores sociais.

A modernidade ocidental tem sido dominada pelo princípio de racionalidade econômica e instrumental. Tal princípio moldou as diversas esferas sociais a partir de padrões tecnológicos, práticas de produção, organizações burocráticas e aparelhos ideológicos de Estado. A instrumentalidade significa que em cada uma dessas esferas prevaleceria uma relação de meios a fins. Já, a racionalidade produtiva, como aprofundamento da anterior, estaria fundada no cálculo 
econômico, na eficiência tecnológica, na eficácia dos sistemas de controle e de previsão e na padronização dos comportamentos sociais.

A racionalidade ambiental, em contraponto, não expressaria uma lógica. Ela seria o resultado de um conjunto de interesses e práticas, nas palavras de Leff, que articulando ordens materiais diversas dão sentido a determinados processos sociais. Esses, por sua vez, expressariam o campo das contradições: entre a lógica capitalista e as leis biológicas e entre os processos ecológicos e as transformações dos sistemas socioambientais. Entrariam em jogo, então, a ecologização da sociedade, a conscientização ecológica um planejamento que viesse a atravessar a administração pública, a participação da sociedade e a reorganização do saber, sendo vitais neste último aspecto tanto a interdisciplinaridade, quanto a área de intervenção. A racionalidade ambiental orientaria heuristicamente, diz Leff, o ambientalismo.

A racionalidade instrumental e tecnológica baseia-se na ciência moderna e no desenvolvimento tecnológico, tendo por objetivo o aumento da certeza, a previsão, e o controle da realidade, e procurando garantir a eficácia dentro de um modelo de meios e fins. Portanto, a racionalidade ambiental implica um questionamento dessa racionalidade científica dominante, especificamente no que refere à ideia de domínio da natureza e de dissolução das externalidades através de uma gestão racional.

A proposta de racionalidade ambiental alternativa a uma racionalidade dominante instrumental capitalista fundamentar-se-ia, para Leff, em quatro racionalidades: a substantiva ou axiológica, a teórico-valorativa, a instrumental-social e a cultural. É a integração entre essas quatro racionalidades, sem hierarquização entre elas, que permite construir uma racionalidade alternativa à racionalidade instrumental capitalista dominante.

A crise ambiental seria, para Enrique Leff, a crise por excelência do tempo presente. Ela não deveria ser interpretada como uma catástrofe ecológica, pois seria efeito de um pensamento com o qual foi construído e - o que é mais importante ainda -, ao mesmo tempo, destruído o mundo em que vivemos. Em outras palavras, a crise ambiental seria a crise do próprio pensamento ocidental. A concepção dominante que se desenvolveu em Ocidente propiciou a prevalência de uma racionalidade científica e instrumental da modernidade, ávida por dominar e controlar a natureza e que teve como uma de suas principais consequências a criação de um mundo fragmentado e coisificado.

A problemática ambiental, para essa perspectiva, situar-se-ia em um nível de análise superior ao colocado pelas interpretações concorrentes analisadas acima. Tal problemática precisa 


\section{Abordagens sociológicas da questão ambiental: contribuições e limites conceituais}

ser inserida no interior de um questionamento mais profundo da ontologia e da epistemologia da civilização ocidental. A constituição social das sociedades ocidentais, junto com a sua forma de conhecer o mundo, deveria ser colocada em causa. Nessa crítica, aparecem como aspectos cruciais a serem questionados o desenvolvimento da ciência instrumental e da razão tecnológica, bem como as noções de domínio da natureza e de centralidade da economia no mundo moderno.

\section{CONSIDERAÇÕES FINAIS}

Nesta seção, apresentam-se as contribuições principais de cada uma das leituras sociológicas da questão ambiental junto com as suas dificuldades conceituais. A contribuição principal da perspectiva sistêmica seria a de considerar a questão ambiental como um todo e como partes que se interrelacionam. Além disso, a importância dada às ações de planejamento constituiria outra originalidade dessa linha de pensamento. Os problemas associados a esta concepção seriam os de reduzir a problemática ambiental a uma questão de custos e recursos, as dificuldades de incorporar o agir dos atores sociais, assim como, o fato de avaliar a crise ambiental apenas como resultado de desequilíbrios de subsistemas e, ainda, a priorização não comprovada da variável crescimento populacional.

A perspectiva valorativa-comunicativa enfatizaria a relevância do modelo dominante de industrialização e consumo capitalistas. O ambientalismo seria introduzido como um conjunto de valores e ideias com força semelhante à das grandes ideologias. A relevância dada à dimensão valorativa do movimento ambientalista é, pode se considerar, a sua principal contribuição. Porém, as dificuldades dessa linha de análise são as de atribuir, principalmente, as mudanças na vontade política dos atores a solução para a problemática ambiental. Visualiza-se, também, uma excessiva confiança de que os valores instrumentais do mercado convergiriam com os valores originários do discurso ecológico. A confiança em alcançar uma razão comunicativa entre interesses contrapostos emergiria, na realidade, com um dilema não resolvido. A ausência de componentes agonísticos, que impõem diferentes sentidos à problemática ambiental, constituiria o elemento mais frágil dessa linha de análise.

A perspectiva das contradições capitalistas apontaria - com base em Marx - diferentemente das análises anteriores a importância dos agentes sociais na explicação da questão ambiental. As contradições entre capitalismo e natureza estariam no centro da explicação. Primeiramente, a contradição que colocaria a busca de lucro e a exploração da força de trabalho, antes de mais nada, 
tendo como consequência a redução do poder aquisitivo e, portanto, a da própria realização do lucro. Em segundo lugar, a contradição que gerar-se-ia quando o incremento dos custos do trabalho, dos recursos naturais, da infraestrutura e do espaço leva a uma diminuição dos lucros marginais. Esse incremento de custos deve-se, em boa medida, à atuação dos movimentos ambientalistas. A contribuição dessa postura teórica estaria em priorizar o agir dos atores sociais, principalmente, os capitalistas, os movimentos ambientalistas. Suas maiores dificuldades podem ser identificadas, no entanto, na hora de avaliar corretamente o agir desses atores. Afinal, não está definido de antemão que empreendimentos capitalistas, que levem em conta custos ambientais e venham a ter como consequência a diminuição de lucros. Políticas empresariais, hoje, por exemplo, podem enveredar por ações de "marketing ambiental" que produzam aumento e não diminuição dos lucros, justamente porque uma estratégia ambientalista pode se constituir como um valor agregado do produto. Outras dificuldades surgiriam da redução da questão ambiental à dimensão econômica, desconsiderando dimensões importantes como a valorativa ou a simbólica.

Como já foi afirmado, a teoria da Sociedade de Risco é uma das linhas de análise mais inovadoras nas ciências sociais contemporâneas. Embora essa leitura abranja outras questões para além da ambiental, esta última representa um tema central por ela abordado. A chamada sociedade do risco seria resultado do desenvolvimento da sociedade moderna e traria com ela perigos que não podem ser controlados. A sociedade do risco implicaria a auto compreensão dos perigos advindos do desenvolvimento da sociedade industrial. A contribuição principal dessa linha teórica consistiria em advertir que perigos e catástrofes, especialmente ecológicas, podem ser resultado de decisões que em princípio procuram o melhor para o desenvolvimento humano. A incerteza contemporânea, a impossibilidade de controle absoluto e as consequências inesperadas da ação configuram elementos de uma teoria que tem muito a dizer sobre a problemática ambiental, suas dificuldades, entretanto, estão associadas ao fato de não distinguir entre interesses contrapostos, e ao fato de universalizar a ideia de sociedade do risco para todas as sociedades contemporâneas. Nesse sentido, poderíamos nos perguntar se a responsabilidade em relação aos danos ambientais seria dividida, então, da mesma maneira entre países ricos e pobres.

A perspectiva da crítica pós-moderna é, semelhante a proposta anterior, uma análise inovadora das ciências sociais contemporâneas, em geral, e da questão ambiental, em particular. Em larga medida, podem ser encontradas nessa concepção elementos, também, presentes nas análises concorrentes vistas anteriormente. Da perspectiva sistêmica incorpora a visão totalizadora da questão ambiental; da abordagem valorativa-comunicativa ela teria incorporado a importância de 


\section{Abordagens sociológicas da questão ambiental: contribuições e limites conceituais}

valores como os de diferença, de diversidade, de democracia e de autonomia, bem como o diagnóstico de predomínio da racionalidade econômica e instrumental no mundo contemporâneo; enquanto que da perspectiva da análise das contradições destacaria o fato de estarmos inseridos em economias capitalistas bem como a crítica ao conceito de desenvolvimento sustentável; em relação a teoria do risco, ressaltaria a relevância outorgada às ameaças que se cernem sobre o planeta. A novidade da concepção da crítica pós-moderna seria a de perceber a problemática ambiental como o confronto de duas racionalidades: a capitalista e a ecológica ou ambiental. Embora se deva colocar a seguinte dúvida: pensar a questão ambiental em termos de uma nova "racionalidade" não seria o mesmo que ser herdeiro do paradigma moderno que Leff questiona? ${ }^{10}$

A novidade residiria, também, porque este confronto não só implicaria classes, grupos e atores sociais, mas, também, paradigmas de conhecimento. A crise ambiental seria uma crise do pensamento ocidental, implicando um questionamento não apenas nos rumos seguidos pela civilização ocidental, mas, também, na sua epistemologia. Assim, nossa reflexão final aponta que a perspectiva da crítica pós-moderna integra, de forma criativa, diversos elementos notados nas outras concepções teóricas examinadas neste artigo. Além disso, essa linha de pensamento adicionaria um elemento substancial: a questão ambiental não é apenas uma relação dos seres humanos com a natureza, é também uma forma de conhecer esta última. Problematizar a questão ambiental é também colocar em suspenso nossa própria forma de conhecê-la.

\section{BIBLIOGRAFIA}

ALTVATER, Elmar. O preço da riqueza. São Paulo: UNESP, 1995.

ALTVATER, Emar. Existe um marxismo ecológico. In: A teoria marxista hoje. Problemas e perspectivas. Borón Atilio A; Amadeo, Jacier; González, Sabrina (Org.). Buenos Aires: CLACSO, 2007.

BECK, Ulrich. La invención de lo político. Para una teoría de la modernización reflexiva. México, FCE, 1999.

FOLADORI , Guillermo. O capitalismo e a crise ambiental. Outubro, São Paulo, v. 5, 2001.

\footnotetext{
${ }^{10}$ Devo esta reflexão ao diálogo com a filósofa colombiana Patrícia Noguera, que propõe o conceito de pensamento ambiental antes que o de racionalidade ambiental. O conceito alternativo implica, para a filósofa, pensar a questão ambiental não apenas a partir de elementos racionais, mas, também, da imaginação, da intuição e de diversas sensibilidades.
} 
NORUS - v1, n.2, jan-jun 2014.

GIDDENS, Anthony; BECK, Ulrich; LASH, Cristopher. Modernização reflexiva: política, tradição e estética na ordem social moderna. São Paulo: Editora da UNESP, 1997.

LEFF, Enrique. Saber ambiental: sustentabilidade, racionalidade, complexidade, poder. 5.ed. Petrópolis, RJ: Vozes, 2001.

LEIS, Hector Ricardo. Ambientalismo: um projeto realista-utópico para a política mundial. In: Meio Ambiente, Desenvolvimento e Cidadania: Desafios para as Ciências Sociais. São Paulo: Cortez, 1998. pp. 15-43.

O'CONNOR, James. Es posible el capitalismo sostenible? In: ALIMONDA, Heitor. Ecologia política, naturaleza, sociedad y utopia. Buenos Aires: CLACSO, 2002. Biblioteca CLACSO Libro: "Ecología Política. Naturaleza, sociedad y utopía", de Héctor Alimonda(2002)

VIEIRA, Paulo Freire. Meio Ambiente, Desenvolvimento e Planejamento. In: Paulo H. F. Vieira; Eduardo Viola; Hector Ricardo Leis; et al. (Org.). Meio Ambiente, Desenvolvimento e Cidadania: Desafios para as Ciências Sociais.2 ed. São Paulo: Cortez, 1998.

Recebido: 04/04/2014.

Aprovado: 15/05/2014. 